\title{
Evaluation of a Newly Formulated Thermoplastic Monomer Free Complete Denture Base Material (Microbiological Study)
}

\author{
Ahmed Abdelhamid ${ }^{1}$, Medhat Ashour ${ }^{2}$, Abdelrahman Mohamed Abdelrahman ${ }^{3}$ \\ ${ }^{1}$ Professor and head of Prosthodonticdepartment, Alexandria University Faculty of Dentistry, Alexandria, Egypt \\ ${ }^{2}$ Professor of Medical laboratory,Beirut Arab University,Faculty of Health Sciences, Tripoli, Lebanon \\ ${ }^{3}$ BDS, MS, Alexandria University, Faculty of Dentistry, Alexandria, Egypt
}

\begin{abstract}
Statement of problem: Information is lacking about tissue reaction of mucosa to theThermoplastic polyamidedentures, as an excellent alternative to conventionally used heat cured acrylic resin dentures. Subjects and Methods: Fourteen Completely Edentulous male patients were selected. Patients were divided into two groups equally. One group was treated using the injectable thermoplastic polyamide resin complete denture base material and the second group was treated using the conventional heat cured acrylic resin (PMMA) complete denture base material. Saliva samples were collected to measure the level of salivary cytokines (TNF- $\alpha$ \& IL-6) using ELISA technique. Data were statistically analyzed. Results: When comparing the two studied groups regarding mean difference of the level of both pro inflammatory salivary cytokines (TNF-a\& IL-6) after delivery of the new denture,group II levels were significantly higher than group I levels at each period separately ( $1 / 2$ hour, 1 hour 2 hours, 1 day, 3 days, 1 week and 2 weeks). Conclusion: Thermoplastic Polyamide denture base material did not elicit an inflammatory process response which might be related to monomer free nature of thermoplastic polyamide denture base material. On the other hand,heat cured acrylic denture base material initiates an inflammatory process response which might be due to residual monomer release.
\end{abstract}

Keywords: Thermoplastic polyamide, Complete denture, SalivaryCytokines, TNF- $\alpha$, IL-6

\section{Introduction}

The denture base is part of a denture that rests on the foundation tissues and to which teeth are attached. [1]

The denture base material should possess several properties including: biocompatibility, good esthetics, high bond strength with available denture teeth, radiopacity, ease of repair, and should also possess adequate physical and mechanical properties. The denture base must be strong enough to allow the prosthesis to withstand functional and parafunctional masticatory forces. [2]

The introduction of acrylic resinPolymethyl methacrylate (PMMA) as denture base material in 1937 was revolutionary. It was found to have a favorable combination of properties that accounts for its popularity of use. Acrylic resins are synthetically obtained materials that can be modeled, packed or injected into molds which turn into solid by chemical reaction (polymerization). They might be heat cured, chemically cured or light cured. [3-5]

Although PMMA as a conventional denture base material is satisfying esthetic demands adequately, this material does not fulfillall the ideal requirements of the prosthesis. That was reflected in the breakage of acrylic denture during service as a result of fatigue failure in the mouth or impact failure out of the mouth. PMMA also has several demerits, including: low thermal conductivity, high porosity, high water absorption, poor wear resistance, volumetric changes and has low modules of elasticity which requires greater bulk than desirable to produce adequate strength. [6-8].
In addition, it is not fully biocompatible with the oral tissues, asthe residual monomer diffuses out of the denture into adjacent oral tissues; this may result in irritation, inflammation, and an allergic response of the oral mucosa. Clinical signs and symptoms most frequently reported include erythema, erosion of oral mucosa, and burning sensation on the mucosa and tongue[9-11]

The residual monomer concentration may also effect on the mechanical properties of the polymer: tensile strength, modulus of elasticity and surface hardness which founded to be lower with greater residual monomer concentration due to the plasticizing effect of the methyl methacrylate. [12-14].

Thermoplastic materials have occupied place for making complete and partial dentures due to the lack of solubility in solvents, high heat resistance and high strength coupled with ductility, toughness, low density, abrasion resistance, and resistance to chemicals effects, use of heat-molding instead of chemical polymerization which control the polymerization shrinkage and its related deformation and biocompatibility through monomer free nature.[15-17]

Soygun et al., [18]studied the mechanical properties of polyamide in comparison with the conventional heat-cured PMMA and fiber reinforced PMMA denture base materials using computer-aided universal testing device and found that the polyamide denture base material had the highest transverse strength and no fracture was observed in these specimens. It was also observed that the values of maximum impact strength were in its highest values for polyamide and was much higher than other groups. This could be attributed to the chemical structure properties which enables it for a 


\section{International Journal of Science and Research (IJSR) \\ ISSN (Online): 2319-7064}

Index Copernicus Value (2013): 6.14 | Impact Factor (2014): 5.611

better force absorption than PMMA.

Hamanaka et al, [19] compared some mechanical properties of two polyamides, one polyethylene terephthalate and one polycarbonate with a conventional heat-polymerized polymethyl methacrylate (PMMA). They reported that all the injection-molded thermoplastic resins had significantly higher impact strengths compared to the conventional PMMA.

Recently,there has been a growing interest in the measurement of cytokines for clinical applications.As Cytokines are directly implicated in various pathophysiological conditions in humans, and their increased production is responsible for their elevated levels in different body fluids and Cytokines concentrations can reflect the severity of some diseases and can be markers of prognosis. [20]

Cytokines are peptide mediators that function as up and down regulators of immunologic, inflammatory, and reparative host responses by regulating the growth, mobility, and differentiation of leukocytes and other defensive cells $[21,22]$.

Cytokines can be divided into pro-inflammatory and antiinflammatory cytokines, pro-inflammatory cytokines(such as InterLeukin-6 and Tumor Necrosis Factor- alpha)regulate leukocyte trafficking, trigger proliferation, and activate vigorous metabolic reactions by these cells. Through these functions, pro-inflammatory cytokines may potentially be involved in immune protection.[23,24]

Bioassay and immunoassay (such as immunoradiometric assay (IRMA) and enzyme-linked immunosorbent assay (ELISA)) are the analytical techniques of choice to measure cytokines. These techniques are used to quantify cytokines in biological fluids (such as blood, saliva, Serum and plasma), cytokine production by whole blood cells, cytokinereceptors, and the intracellular levels of cytokines [25]

This study was conducted tomeasure the level of salivary cytokines (TNF- $\alpha$ \& IL-6) in patients with complete denture before \& after delivery using thermoplastic polyamide denture base material \& conventional heat cure acrylic resin.

\section{Subjects and Methods}

Fourteen Completely Edentulous male patients were selected from Prosthodontic Department, Faculty of Dentistry, Alexandria University.

The fourteen selected patients were divided equally into two groups:

- Group I (study group): received complete dentures, which were constructed of Injectable thermoplastic polyamide resin (Vertex $^{\mathrm{TM}}$ ThermoSens Rigid, Vertex-Dental B.V. Headquarters The Netherlands) using Injection Molded Technique.

- Group II (control group): received complete dentures, which were constructed of conventional poly methyl methacrylate acrylic resin using the compression molding technique.
All selected patients were completely edentulous aged from 40 to 60 years with no previous denture experience. They were non-smokers, with good oral hygiene and free from any systemic diseases. They had no signs of inflammation (such as: redness \& swelling). They had well-formed maxillary and mandibular residual ridge covered with healthy mucosa and acceptable maxillo-mandibular relationship.

All clinical \& laboratory steps for denture construction were done for every patient according to standardized conventional technique.

For group I, complete dentures were constructed using the thermoplastic polyamide resin material.supplied as pre dosed granules in aluminum cartridges which were available in different sizes; medium, large and extra-large, the thermoplastic polyamide was available in a range of colors.

The thermoplastic polyamide is based on injection technique. which can be done with an automatic or manual injection machine. Each maxillary and mandibular cast was invested in a special flask which consists of two indexed halves and a round hole through which the injectable material was thermo-pressed.

The stone was used as an investing material, after painting the flask with a separating medium. This stone was mixed (100g of stone :20 $\mathrm{ml}$ of water) and poured into the lower half of the flask then the flask was pushed into the stone with its back edge facing the flask hole.

After setting of stone, a rod shaped wax sprue was attached to the waxed up trial denture (Sprue wax soft $9.5 \mathrm{~mm}$ for the main sprue was used). (Figure1). The Stone in the lower flask half was isolated using alginate separation fluidfollowed by pouring the stone in the upper flask half.

The two halves were merged and flask was closed and placed in the machine for wax elimination, the flask was heated to $70^{\circ} \mathrm{C}$ for about 10 minutes. Then we removed the base plate and modelling wax after opening the flask and rinsed the stone in the flask with clean boiling water to remove modelling wax remnants.

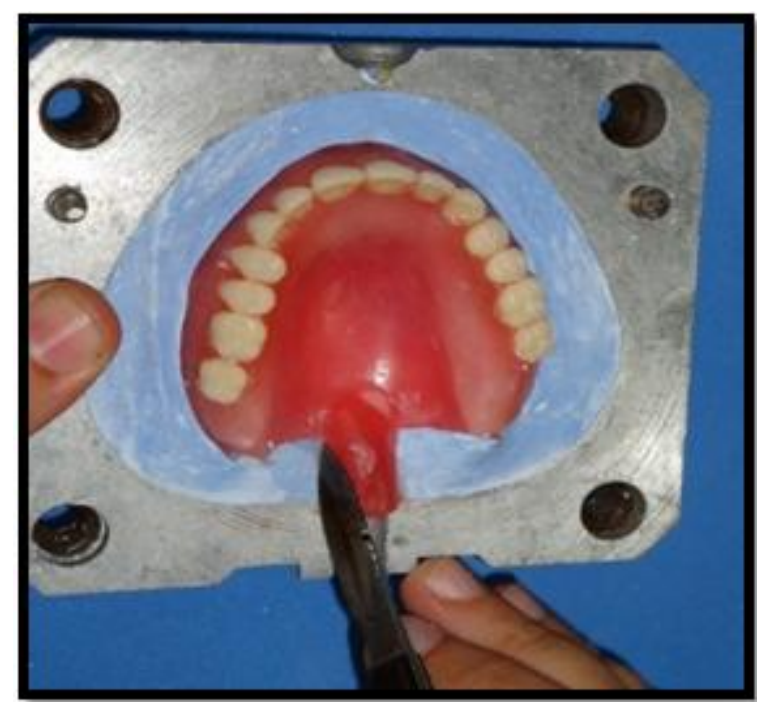

Figure 1: sprue attachment to the waxed up trial maxillary denture 


\section{International Journal of Science and Research (IJSR) \\ ISSN (Online): 2319-7064}

Index Copernicus Value (2013): 6.14 | Impact Factor (2014): 5.611

The flask was dried and the injectable surfaces were treated with a separation fluid suitable for injection technique.

Before placing the cartridge in the injection machine (Thermoject 22 machine, Vertex-Dental B.V. Headquarters The Netherlands), we sprayed the cartridge with silicone spray.

The flask was placed on top of the injection machine, both cartridge and flask were heated up. The material in the cartridge was injected automatically after pre heating time (20 minutes)has elapsed at $310^{\circ} \mathrm{C}$.

The molten resin was injected under pressure 6.3 Barr into the pre heated mold until it Was filled. The pressure was automatically kept constant for another one minute to compensate setting contraction. (Figure2).

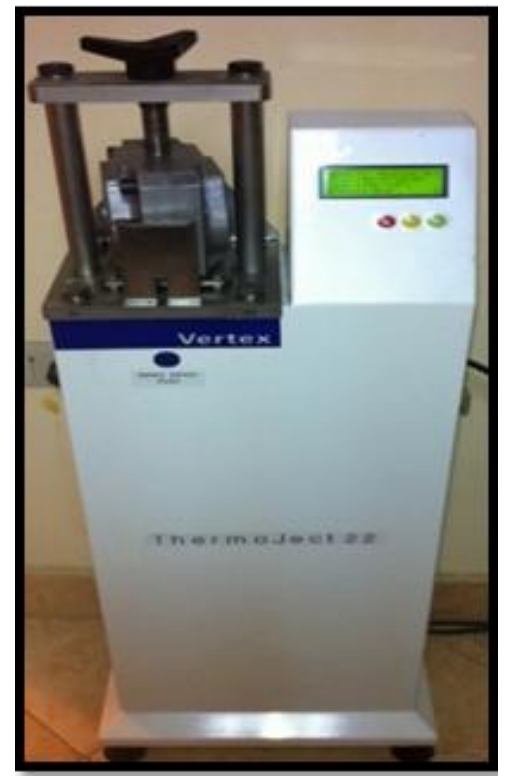

Figure 2: The injection molding machine

After the flask was removed from the injection machine, the flask was left to bench cooling for at least 30 minutes.

The dentures were finished using a cutter at low speed and low pressure to cut off the sprues and remove any excess. Rubber disks were used for a pre polishing finish, the dentures were polished using a fine-grained pumice and brushes.(Figure3,4).

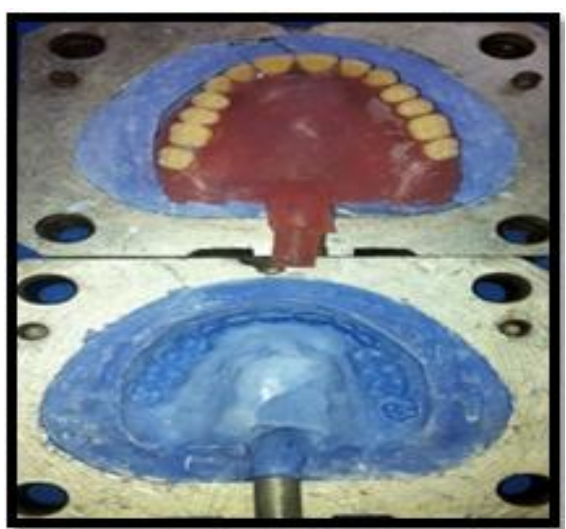

Figure 3: Processed thermoplastic polyamide maxillary denture with attached sprue

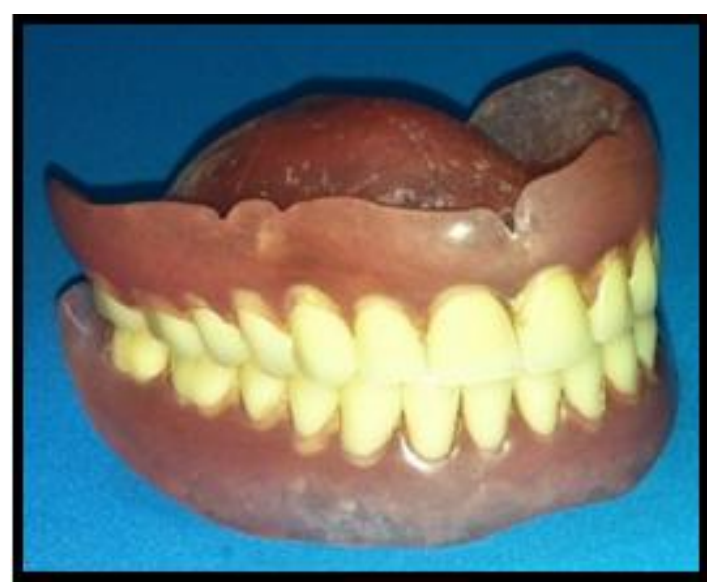

Figure 4: Final finished thermoplastic polyamide maxillary and mandibular dentures

Complete denture constructed of Heat cure acrylic resin (PMMA) were processed using the conventional compression molding technique and cured by long curing cycle. The dentures were finished and polished in the conventional manner.

\section{Salivary Cytokines Measurement}

Collection of whole unstimulated saliva (WUS) from every patient in the two groupswas done using standard techniques according to Navazesh cytokine profiles. [26]

Salivary samples were obtained in the morning by requesting participants to swallow first, then tilt their head forward, and expectorate all saliva into a $5 \mathrm{ml}$ sterile centrifuge tubes for 5 min without swallowing.

The first sample was collected directly before delivery of the new denture. Other samples were collected after delivery of the new denture at the same day of delivery (half hour, one hour \& two hours), one day, three days, one week and two weeks after denture delivery.

Participants were instructed not to eat, drink, or use mouth rinse at least 2 hours prior to the day of salivary sample collection.

The saliva samples were frozen at $-70^{\circ} \mathrm{C}$ till used later on for cytokine detection by the ELISA method. All samples were centrifuged at $4500 \mathrm{~g}$ for $20 \mathrm{~min}$ and supernatant of each sample was separated to be used in the assay.

Cytokines in saliva samples were assayed using Enzymelinked immunosorbent assay (ELISA):

- TNF- $\alpha$ was measured using TNF- $\alpha$-ELISA. (TNF- $\alpha$ Elisa kit-96 T, BE55001 - I B L International - Hamburg, Germany)

- IL-6 was measured using IL-6- ELISA. (IL-6 Elisa kit-96 T, BE53061 - I B L International - Hamburg, Germany).

The resulting data were fed to the computer and analyzed using IBM SPSS software package version 20.0. Quantitative data were described in Newton as range (minimum and maximum) mean, standard deviation. The distributions of quantitative variables were tested for normality using Kolmogorov-Smirnov test, Shapiro-Wilk test and D'Agstino test and revealed a normally distributed

\section{Volume 5 Issue 2, February 2016}




\section{International Journal of Science and Research (IJSR) \\ ISSN (Online): 2319-7064 \\ Index Copernicus Value (2013): 6.14 | Impact Factor (2014): 5.611}

data. Accordingly, Comparison between two independent data was done using independent t-test; Comparison between multiple data was done using ANOVA with repeated measures and Post Hoc test was assessed using Dunnett's test. Significance test.Results were quoted as two-tailed probabilities. Significance of the obtained results was judged at the $5 \%$ level. A p-value of less than 0.05 was considered statistically significant.

\section{Ethical Approval}

This study protocol was approved by the research ethics committee of the Faculty of Dentistry, Alexandria University, Egypt.

\section{Ethics, Consent and Permissions}

All the patients signed an informed consent form before participation in this study.

\section{Consent to Publish}

All the patients who participated in the study provided consent to publish the data obtained from them during the study.

\section{Results}

As shown on table (1), the mean difference of the level of salivary tumor necrosis factor alpha (TNF- $\alpha$ ) of group I was in its lowest value after two weeks of delivery of the new denture $(0.02 \pm 0.00) \mathrm{pg} / \mathrm{ml}$ and highest after one day of delivery $(0.33 \pm 0.10) \mathrm{pg} / \mathrm{ml}$.

It showed slight increase insignificantly from the beginning at the same day and after 1day of delivery. Then it decreased insignificantly after 3 days and 1 week of delivery. After two weeks it decreased showing statistically non-significant difference from the baseline.

The mean difference of the level of salivary tumor necrosis factor alpha (TNF- $\alpha$ ) of group II was in its lowest value after two weeks of delivery of the new denture $(0.12 \pm 0.06)$ $\mathrm{pg} / \mathrm{ml}$ and highest after one day of delivery $(11.51 \pm 0.40)$ $\mathrm{pg} / \mathrm{ml}$.

It was highly increased from the beginning at the same day and after 1day of delivery. Then it was declined significantly after 3 days and 1 week of delivery. After two weeks it decreased close to normal value showing statistically non- significant difference from the baseline.

When comparing the mean difference of the level of salivary (TNF- $\alpha$ ) for patients of both groups after delivery (half hour, one hour, two hours, 1 day, 3 days, 1 week and 2 weeks). it was found that group II was significantly higher than group I at all periodic follow up $\mathrm{P}=\left(0.001^{*}, 0.0013^{*}\right.$, $0.0015^{*}, 0.001^{*}, 0.0013^{*}, 0.0015^{*}$ and $\left.0.001^{*}\right)$, respectively.

As shown on table (2), the mean difference of the level of salivary Interleukin 6 (IL - 6) of group I was in its lowest value after two weeks of delivery of the new denture $(0.01 \pm 0.02) \mathrm{pg} / \mathrm{ml}$ and highest after one day of delivery $(0.22 \pm 0.02) \mathrm{pg} / \mathrm{ml}$

it showed slight increase insignificantly from the beginning at the same day and after 1 day of delivery. Then it decreased insignificantly after 3 days and 1 week of delivery. After two weeks it decreased showing statistically non-significant difference from the baseline.

the mean difference of the level of (IL-6) of group II was in its lowest value after two weeks of delivery of the new denture $(0.05 \pm 0.05) \mathrm{pg} / \mathrm{ml}$ and highest after one day of delivery $(4.99 \pm 0.40) \mathrm{pg} / \mathrm{ml}$.

It was highly increased insignificantly from the beginning at the same day and after 1day of delivery. Then it was declined insignificantly after 3 days and 1 week of delivery. After two weeks it decreased close to normal value showing statistically non-significant difference from the baseline.

When comparing the mean salivary level of (IL-6) for patients of both groups after delivery (half hour, one hour, two hours, 1 day, 3 days, 1 week and 2 weeks). it was found that group II was significantly higher than group I at all periodic follow up $\mathrm{P}=\left(0.001 *, 0.0016^{*}, 0.0021^{*}, 0.0013^{*}\right.$, $0.001 *, 0.0021 *$ and $0.0022 *)$, respectively.

\section{Discussion}

The patient selection for this study was restricted to male patients to avoid any influence of sex hormone variations on the oral epithelium, with average age ranging from 40 to 60 years. The patients beyond 60 years of age were not included in this study because of probable changes which may occurred in oral mucosa due to senility. Patients whose histories revealed no systemic disorders were selected to eliminate the possible influence of systemic diseases and drug intake on oral mucosal tissues.[27,28].

Table 1: Comparison between the two studied groups regarding mean difference of salivary TNF - $\alpha$ in $\mathrm{pg} / \mathrm{ml}$ at different period of follow up

\begin{tabular}{|c|c|c|c|c|c|c|c|c|c|c|c|}
\hline & & $\begin{array}{c}\text { Before } \\
\text { insertion } \\
\text { (Baseline) }\end{array}$ & $1 / 2$ hour & 1 hour & 2 hours & 1 day & 3 days & 1 weeks & 2 weeks & & \\
\hline \multirow{2}{*}{$\underset{\text { I }}{\text { Group }}$} & Min. - Max. & $5.58-6.94$ & $0-0.1$ & $0-0.1$ & $0-0.3$ & $0.2-0.5$ & $0-0.2$ & $0-0.1$ & $0-0$. & $\mathbf{F}$ & 2.98 \\
\hline & Mean \pm SD & $6.33 \pm 0.46$ & $0.04 \pm 0.04$ & $0.05 \pm 0.04$ & $0.10 \pm 0.11$ & $0.33 \pm 0.10$ & $0.09 \pm 0.07$ & $0.06 \pm 0.05$ & $0.02 \pm 0.00$ & $\mathbf{P}$ & 0.13 \\
\hline \multirow{2}{*}{$\begin{array}{c}\text { Group } \\
\text { II }\end{array}$} & Min. - Max. & $5.71-7.63$ & $0.18-0.67$ & $0.55-1.3$ & $1.85-2.34$ & $11.03-11.99$ & $4.22-5.28$ & $0.27-1.13$ & $0.07-0.21$ & $\mathbf{F}$ & 18.69 \\
\hline & Mean \pm SD & $6.70 \pm 0.69$ & $0.31 \pm 0.16$ & $0.89 \pm 0.27$ & $2.00 \pm 0.16$ & $11.51 \pm 0.40$ & $4.76 \pm 0.37$ & $0.66 \pm 0.32$ & $0.12 \pm 0.06$ & $\mathbf{P}$ & $0.001 *$ \\
\hline $\mathrm{P}$ & & & $0.001 *$ & $0.0013 *$ & $0.0015^{*}$ & $0.001 *$ & $0.0013 *$ & $0.0015 *$ & $0.001 *$ & & \\
\hline
\end{tabular}


International Journal of Science and Research (IJSR)

ISSN (Online): 2319-7064

Index Copernicus Value (2013): 6.14 | Impact Factor (2014): 5.611

$\mathrm{F}$ : value for $\mathrm{F}$ test (ANOVA)

Statistically significant at $\mathrm{p} \leq 0.05$

Table 2: Comparison between the two studied groups regardingmean differenceof salivary IL-6 in pg/ml at different period of follow up.

\begin{tabular}{|c|c|c|c|c|c|c|c|c|c|c|c|}
\hline & & $\begin{array}{c}\text { Before } \\
\text { insertion } \\
\text { (Baseline) }\end{array}$ & $1 / 2$ hour & 1 hour & 2 hours & 1 day & 3 days & 1 weeks & 2 weeks & & \\
\hline \multirow{2}{*}{$\begin{array}{c}\text { Group } \\
\text { I }\end{array}$} & Min. - Max. & $1.89-2.71$ & $0.01-0.05$ & $0.06-0.08$ & $0.1-0.13$ & $0.19-0.25$ & $0.06-0.11$ & $0.03-0.06$ & $-0.02-0.03$ & $\mathbf{F}$ & 2.98 \\
\hline & Mean \pm SD & $2.20 \pm 0.28$ & $0.02 \pm 0.02$ & $0.07 \pm 0.01$ & $0.12 \pm 0.01$ & $0.22 \pm 0.02$ & $0.09 \pm 0.02$ & $0.04 \pm 0.01$ & $0.01 \pm 0.02$ & $\mathbf{P}$ & 0.064 \\
\hline \multirow{2}{*}{$\begin{array}{c}\text { Group } \\
\text { II } \\
\end{array}$} & Min. - Max. & $1.92-2.76$ & $0.08-0.2$ & $0.22-0.45$ & $0.43-0.83$ & $4.54-5.48$ & $2.04-3.76$ & $0.16-0.2$ & $0-0.14$ & $\mathbf{F}$ & 32.65 \\
\hline & Mean \pm SD & $2.40 \pm 0.29$ & $0.11 \pm 0.05$ & $0.34 \pm 0.10$ & $0.69 \pm 0.14$ & $4.99 \pm 0.40$ & $2.84 \pm 0.69$ & $0.17 \pm 0.02$ & $0.05 \pm 0.05$ & $\mathbf{P}$ & $0.0001 *$ \\
\hline $\mathrm{P}$ & & & $0.001 *$ & $0.0016^{*}$ & $0.0021 *$ & $0.0013 *$ & $0.001 *$ & $0.0021 *$ & $0.0022 *$ & & \\
\hline
\end{tabular}

F: value for F test (ANOVA) pg

Statistically significant at $\mathrm{p} \leq 0.05$

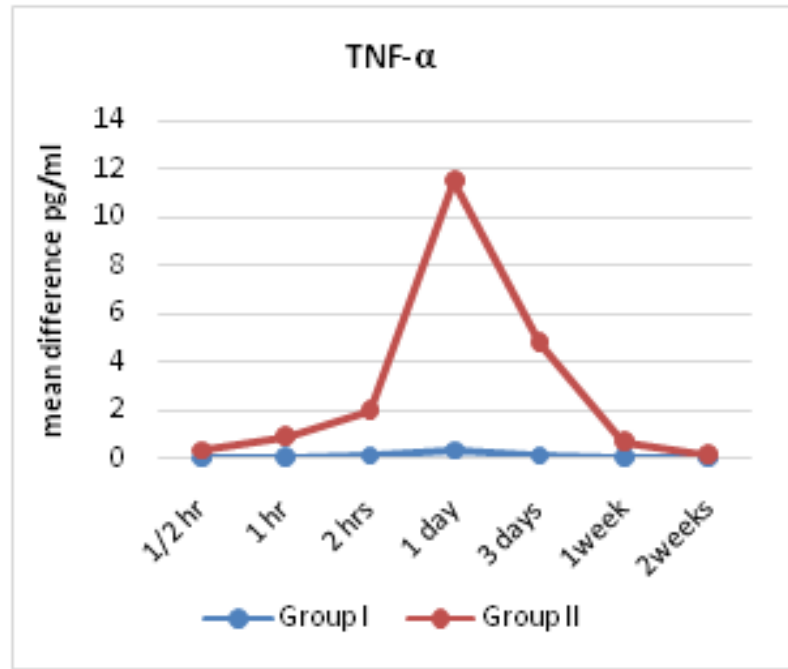

Figure 5:Comparison between the two studied groups regarding mean difference of salivary TNF - $\boldsymbol{\alpha}$ at different period of follow up.

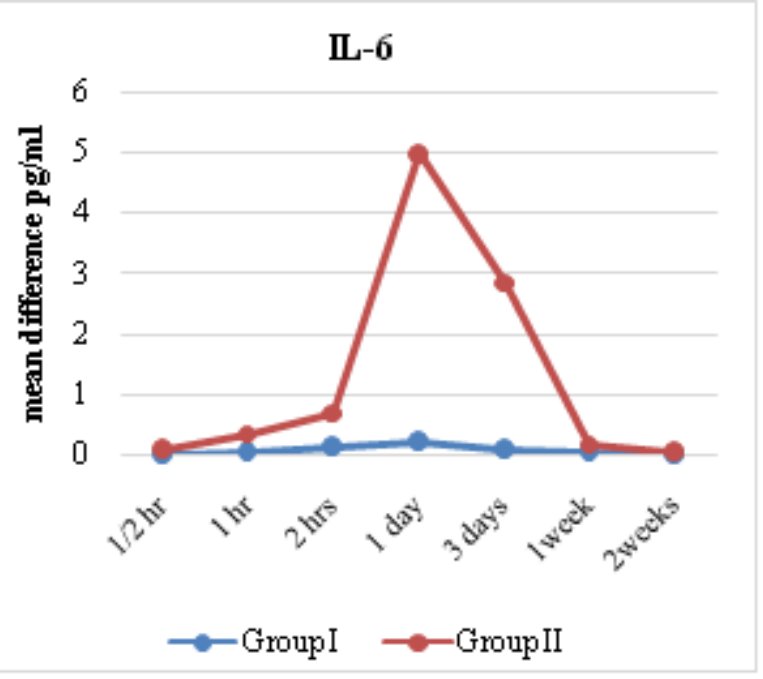

Figure 6: Comparison between the two studied groups regarding mean difference of salivary IL-6at different period of follow up.

The fourteen selected Patients were divided into two groups equally. One group was treated using the injectable thermoplastic polyamide resin complete denture base material and the second group was treated using the conventional heat cured acrylic resin (PMMA) complete denture base material.

All steps of fabricating complete denture were done as conventional technique. Clinical remount was done to adjust the occlusion to avoid the irritation resulting from cuspal interference. [29].

The long curing cycle of compression molding technique was selected to process acrylic dentures as it was concluded to give the lowest value of residual monomer. [30,31].

Before delivery of the denture to patients of group II, the Acrylic dentures were soaked in water for one day to decrease leaching out of monomer inside the patient's mouth with its irritating and adverse effects on oral mucosa. $[32,33]$.

Patients were shown how to clean their dentures, in addition to oral and written instructions. Denture hygiene protocol comprised of: (i) brushing internal and external surfaces of the dentures for 2 min with a nonabrasive denture cleanser then rinsing with water. (ii) Cleaning the mouth after removing the dentures (v) Soaking dentures overnight in a mild antiseptic denture soaking solution. (vi) Rinsing dentures before putting them back in the mouth.[34].

Saliva samples were collected from patients of both groups I and II at 8 different periods; before denture delivery and after denture delivery (1/2, 1 and 2 hours, 1 day, 3 days, 1 week, 2 weeks) for both microbiological\&immunological study. Salivary cytokines were detected and quantified by the enzyme linked immunosorbent assay (ELISA) for its excellent analytical performance and the ability to be automated. [35].

Detection of salivary cytokines levels before delivery of the new denture was important since there were no estimated values for normal levels of cytokines in the saliva of healthy edentulous patients in the literature. and we need these values to compare it with the level of cytokines after delivery of the new denture and thus to conclude the tissue reaction of mucosa to the denture base materials.

In this study there was no change in the levels of proinflammatory salivary cytokines (TNF- $\alpha$ and IL-6) of group I patients, this may be due to absence of residual monomer. 


\section{International Journal of Science and Research (IJSR) \\ ISSN (Online): 2319-7064 \\ Index Copernicus Value (2013): 6.14 | Impact Factor (2014): 5.611}

These results agree with Ramadan [36]. who found that absence of any traces of monomer of thermoplastic polyamide when using Infrared-spectroscopic analysis.

On the other hand, the levels of these cytokines in the saliva of group II patients increased insignificantly after delivery at the same day. and then increased significantly 1 day after delivery.After two weeks it decreased close to normal value showing statistically non-significant difference from the baseline.

The immunological \& microbiological study of this research illustrated that patients received acrylic complete denture were associated with significant high levels of proinflammatory salivary cytokines (TNF- $\alpha$ and IL-6) in comparison to their corresponding levels in the thermoplastic polyamide complete denture patients.

The high levels of pro-inflammatory salivary cytokines (TNF- $\alpha$ and IL-6) that were found in saliva of control group patients may be linked to their protective effect against tissue inflammation caused by release of residual monomer. [37].

These results agree with Bural et. [11] who found that residual monomer continues to release throughout 7 days and leaching concentrations markedly reduced after 2 days.

The results are also in agreement with Lung and Darvell[12] they found that Most residual monomer was lost in the first few days of insertion but became almost constant after 2 weeks.

\section{Conclusion}

Within the limitations of this study, it could be concluded that:

- Heat cured acrylic denture base material is associated with increase in pro inflammatory salivary cytokines (TNF- $\alpha \&$ IL-6) from the beginning of denture delivery which declined by the end of follow up period. On the other hand, thermoplastic polyamide denture base material is associated with no change in these levels.

- Heat cured acrylic denture base material initiates an inflammatory process response which might be due to residual monomer release.

- Thermoplastic Polyamide denture base material did not elicit an inflammatory process response which might be related to monomer free nature of thermoplastic polyamide denture base material.

\section{References}

[1] The Academy of Prosthodontics. The Glossary of prosthodontic terms. J Prosthet Dent. 2005; 94:10-92.

[2] Diwan R. Materials Prescribed in the Management of Edentulous Patients. In: Zarb G, Bolander CL. Prosthodontic Treatment for Edentulous Patients. Ed 12. St. Louis, C.V. Mosby, 2004: 190-207.

[3] Craig RG, Powers JM. Restorative dental materials. 11th ed. St. Louis, Missouri: Elsevier; 2002. 640-4 p.
[4] Hiromori K, Fujii K, Inoue K. Viscoelastic properties of denture base resins obtained by underwater test. J Oral Rehabil. 2000; 27:522-31.

[5] Parvizi A, Lindquist T, Schneider R, Williamson D, Boyer D, Dawson D V. Comparison of the dimensional accuracy of injection-molded denture base materials to that of conventional pressure-pack acrylic resin. J Prosthodont. Wiley Online Library; 2004;13(2):83-9.

[6] John J, Gangadhar S a., Shah I. Flexural strength of heat-polymerized polymethyl methacrylate denture resin reinforced with glass, aramid, or nylon fibers. J Prosthet Dent. 2001;86(4):424-7.

[7] Narva KK, Lassila L V., Vallittu PK. The static strength and modulus of fiber reinforced denture base polymer. Dent Mater. Elsevier; 2005 May 5;21(5):421-8.

[8] McCabe JF, Walls AWG. Applied dental materials. 9th ed. Singapore: Blackwell Publishing Ltd. 2008.

[9] Ivkovi N, Božovi D, Risti S. The Residual Monomer in Dental Acrylic Resin and Its Adverse Effects. Contemp Mater. 2013; 1:86-91.

[10] Bettencourt AF, Neves CB, de Almeida MS, Pinheiro LM, Oliveira SAE, Lopes LP, et al. Biodegradation of acrylic based resins: A review. Dent Mater. 2010;26(5)171-80.

[11]Bural C, Aktaş E, Deniz G, Ünlüçerçi Y, Kızılcan N, Bayraktar G. Effect of post-polymerization heattreatments on degree of conversion, leaching residual MMA and in vitro cytotoxicity of autopolymerizing acrylic repair resin. Dent Mater. 2011;27(11):1135-43.

[12] Lung CYK, Darvell BW. Minimization of the inevitable residual monomer in denture base acrylic. Dent Mater. 2005 Dec;21(12):1119-28.

[13] Jerolimov V, Huggett R, Brooks SC, Bates JF. The effect of variations in the polymer/monomer mixing ratios on residual monomer levels and flexural properties of denture base materials. Quintessence Dent Technol. 1985;9(7):431.

[14] Oku J. Impact properties of acrylic denture base resin. Effect of temperature and residual monomer on impact characteristics. Dent Mater J. 1989;8(2):186-93.

[15] Prashanti E, Jain N, Shenoy VK, Reddy JM, Shetty BT SS. Flexible dentures: A flexible option to treat edentulous patients. J Nepal Dent Assoc. 2010;11(1):85-7.

[16] MacGregor AR, Graham J, Stafford GD, Huggett R. Recent experiences with denture polymers. J Dent. Elsevier; 1984;12(2):146-57.

[17] Meijer GJ, Wolgen PJ. Provisional flexible denture to assist in undisturbed healing of the reconstructed maxilla. J Prosthet Dent. 2007 Oct;98(4):327-8.

[18] Soygun K, Bolayir G, Boztug A. Mechanical and thermal properties of polyamide versus reinforced PMMA denture base materials. J AdvProsthodont. 2013;5(2):153-60.

[19] Hamanaka I, Takahashi Y, Shimizu H. Mechanical properties of injection-molded thermoplastic denture base resins. ActaOdontol Scand. 2011;69(2):75-9.

[20] Jones B. The Immune Response. In: Samaranayake L, editor. Essential microbiology for dentistry. 4th ed. Churchill Livingstone; 2012.

[21] Hieshima K, Ohtani H, Shibano M, Izawa D, Nakayama T, Kawasaki Y, et al. CCL28 has dual roles in mucosal immunity as a chemokine with broad-spectrum 


\section{International Journal of Science and Research (IJSR) \\ ISSN (Online): 2319-7064}

Index Copernicus Value (2013): 6.14 | Impact Factor (2014): 5.611

antimicrobial activity. J Immunol. 2003 Feb $1 ; 170(3): 1452-61$

[22] Playfair J., Chain B. Immunology at a Glance. 10th ed. Wiley-Blackwell; 2012.

[23] Dongari-Bagtzoglou A, Fidel PL. The host cytokine responses and protective immunity in oropharyngeal candidiasis. J Dent Res. 2005 Nov;84(11):966-77.

[24]Heney D, Whicher JT. Factors affecting the measurement of cytokines in biological fluids: implications for their clinical measurement. Ann ClinBiochem. 1995 Jul;32 (Pt 4):358-68

[25] Benyoucef S, Hober D, Shen L, Ajana F, De Groote D, Gérard Y, et al. TNF alpha production by whole blood from HIV-1 infected patients. PatholBiol (Paris). 1996 May;44(5):393-6.

[26] Navazesh M. Methods for Collecting Saliva. Annals of the New York Academy of Sciences, 1993; 694: 72-7.

[27] Jani RM, Bhargava K. A histologic comparison of palatal mucosa before and after wearing complete dentures. J Prosthet Dent. 1976 Sep;36(3):254-60.

[28]Zimmermann ER, Zimmermann AL. Effects of race, age, smoking habits, oral and systemic disease on oral exfoliative cytology. J Dent Res. 1965 Jan; 44:627-31.

[29] Hochstedler JL, Shannon JL. A time-saving method for performing a clinical remount procedure with complete dentures. J Prosthet Dent. 1995 Jul;74(1):39-41.

[30] Golbidi F, Asghari G. The Level of Residual Monomer in Acrylic Denture Base Materials. Res J Biol Sci. 2009;4(2):244-9.

[31] Bayraktar G, Guvener B, Bural C, Uresin Y. Influence of polymerization method, curing process, and length of time of storage in water on the residual methyl methacrylate content in dental acrylic resins. J Biomed Mater Res Part B ApplBiomater. 2006;76(2):340-5.

[32] Urban VM, Machado AL, Vergani CE, Giampaolo ET, Pavarina AC, de Almeida FG, et al. Effect of water-bath post-polymerization on the mechanical properties, degree of conversion, and leaching of residual compounds of hard chairside reline resins. Dent Mater. 2009;25(5):662-71.

[33] Urban VM, Machado AL, Oliveira R V, Vergani CE, Pavarina AC, Cass QB. Residual monomer of reline acrylic resins. Effect of water-bath and microwave postpolymerization treatments. Dent Mater. 2007 Mar;23(3):363-8.

[34] Paranhos HF, da Silva CH, Venezian GC, Macedo LD, de Souza RF. Distribution of biofilm on internal and external surfaces of upper complete dentures: the effect of hygiene instruction. Gerontology. 2007;24(3):162-8.

[35] Bienvenu J. Exploration of cytokines in inflammation in biological fluids. C R SeancesSocBiol Fil 1995; 189: 545-55.

[36] Ramadan LA. Evaluation of the Thermoplastic Resin as a Resilient Denture Base Material. MSc Thesis, Department of Removable Prosthodontics, Faculty of Dentistry, Alexandria University, 2012.

[37] Vallittu PK, Miettinen V, Alakuijala P. Residual monomer content and its release into water from denture base materials. Dent Mater. 1995;11(6):338-42.

\section{Author Profile}

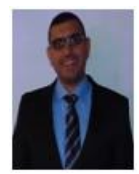

Abdelrahman Mohamed Abdelrahman,received the B.D.S. in Dental and Oral Surgery from Alexandria University, faculty of dentistry 2006. During 20062007, he practiced in Ministry of Health. During 2009. 2016, he educated for M.S degree in prosthodontics in prosthodontic department, faculty of dentistry. Alexandria University. 